\title{
Health Care Organization
}

National Cancer Institute

\section{Source}

National Cancer Institute. Health Care Organization. NCI Thesaurus. Code C43960.

An org anization that provides healthcare services or that is involved in the provision of health care activities. Groupings or subdivisions of an organization, such as departments, may also be considered as organizations where there is a need to identify them. 